\title{
Intersecting Flows of Language and Literacy: A Case Study of One Transnational Youth in the Cloud and in the Classroom ${ }^{1}$
}

\section{(Cruzando flujos de idiomas y alfabetización: estudio de caso de una joven transnacional en la nube y en clase)}

Elizabeth Dillard-Paltrineri ${ }^{2}$

University of Minnesota, Estados Unidos

\begin{abstract}
What youth do online is often dismissed as solely social and superficial, a waste of time and certainly not academic. Many transnational youth use sophisticated, multimodal, and multilingual literacy skills to navigate these physical and virtual spaces. Calling on concepts of flows and scapes, as well as sociocultural notions of mediation, this case study investigates the digital literacy practices of transnational youth. A description is provided of see how these practices flow between (and simultaneously mediate further participation in) official and unofficial spaces of learning.

\section{resumen}

Las actividades en línea de los jóvenes se consideran pasatiempos, y no actividades académicas. Muchos jóvenes transnacionales navegan los espacios físicos y virtuales usando destrezas de alfabetización complejas,

1 Elaborado con base en la ponencia presentada por la autora en el IV Congreso Internacional de Lingüística Aplicada, llevado a cabo en mayo de 2013, en el Campus Omar Dengo, de la Universidad Nacional de Costa Rica. Recibido: 19 de mayo de 2012; aceptado: 30 de agosto de 2012.

2 Correo electrónico: dilla043@umn.edu
\end{abstract}

$$
L_{\text {etras }} 52 \text { (2012), ISSN 1409-424X }
$$


multimodales y multilingües. Mediante los conceptos de flujos y scapes, mediación y teorías socioculturales, este estudio de caso investiga las prácticas de alfabetización digital de jóvenes transnacionales. Describe las formas en que éstas destrezas fluyen ( $\mathrm{y}$, simultáneamente, median más participación) entre espacios de aprendizaje oficiales y no oficiales.

Keywords: transnational youth, digital literacy, sociocultural mediation, second language acquisition, heritage language maintenance

Palabras clave: joven transnacional, alfabetización digital, adquisición y aprendizaje de un segundo idioma, mantenimiento del idioma materno

Located within the powerful forces of globalization, today's transnational youth are simultaneously geographically displaced yet digitally reconnected. Their lives are multisited and multilayered. Because of and through the medium of a constantly evolving online world, transnational youth are able to both maintain and extend their connection to communities near and far-and their associated culture(s) and language(s)-in hitherto unimaginable ways. At the same time, these online spaces serve as locations for the establishment of new communities, the development of literacy, and acquisition of new languages. Because of their centrality and thus saliency in the lives of youth, these online spaces and their mediating power warrant investigation. The current study aims to uncover a small portion of the web of literacy-based connections spanning home, school, and the on- and off-line spaces in between. Specifically, I ask: How do digital literacy practices mediate activities related to both first language maintenance and second language learning?

To this end, I begin by providing a brief review of the literature and a conceptual background for research into how digital literacy skills mediate English language learning and home language maintenance. I discuss Arjun Appadurai's useful concepts of flows and scapes, framing them within the larger context of sociocultural mediation. I then move to a discussion of methodology and the case study itself, finishing with implications for language education. 


\section{Review of the Literature}

A recently published review of the literature by Lam and Warriner synthesized the "emerging body of empirical studies that address various aspects of language and literacy practices as they are intertwined with issues of cross-border relations and mobility." ${ }^{\text {3 }}$ They examined 48 empirical studies which ranged in time period from 1994 to 2012. Lam and Warriner organized their review, and the pertinent transnational practices, into three thematic categories: families and communities, youth and educational spaces, and finally, transnational media. I now turn to a discussion of those recent studies that focused on the use of media by youth and families to make transnational connections.

Because I am interested in mediation, I viewed these studies through the lens of sociocultural theory, specifically identifying what was mediated by digital media in each study. The most common pattern was, not surprisingly, a use of digital media to mediate and facilitate social connections. Lam looked at the instant messaging (IM) practices of a 17-year-old Chinese immigrant to the United States. She found that the youth was able to creatively leverage various orthographic and linguistic knowledges of English, Mandarin, and Cantonese to build relationships in multiple networks across various countries. ${ }^{4}$ Sánchez and Salazar found that second generation Latina adolescents searched out opportunities to develop computer skills in order to communicate with friends and family across the border in their home country of Mexico. ${ }^{5}$ In this case, digital literacy mediated transnational social connections for the entire family. In a similar study, de la Piedra examined the literacy practices of

3 Wan Shun Eva Lam and Doris Warriner. "Transnationalism and Literacy: Investigating the Mobility of People, Languages, Texts, and Practices in Contexts of Migration," Reading Research Quarterly 47, 2 (2012): 191.

4 Wan Shun Eva Lam. "Multiliteracies on instant messaging in negotiating local, translocal, and transnational affiliations: A case of an adolescent immigrant," Reading Research Quarterly 44, 4 (2009): 377-397.

5 Patricia Sánchez and Malena Salazar. "Transnational Computer Use in Urban Latino Immigrant Communities Implications for Schooling," Urban Education 47, 1 (2012): 90-116. 
adolescents and women from the Texas-Mexico border region. Like Sánchez and Salazar, de la Piedra found that digital media mediated the "renewing and maintaining [of] social relationships across the border." ${ }^{\prime \prime}$ And, as with Sánchez and Salazar, de la Piedra found that youth technological familiarity actively mediated parental learning and use of computer technology.

Researchers also found the opposite to be true. In some cases it was the parents who were utilizing media (most often satellite television) to mediate the language learning and/or lanugage maintenance of their children. For example, Cruickshank's 2006 longitudinal study challenged many assumptions about immigrant families, including that of uni-directional language flows: English from children to parents, and home country language(s) from parents to children. ${ }^{7}$ Situated in suburban Sydney, the study found that the parents would use Arabic language videos as a way to expose their kids to spoken Arabic. Interestingly, these kids, though labeled as "non-readers" by their teachers, were completing roughly thirty hours per week of homework for Arabic community school. Their literacy development in both English and Arabic mediated parental literacy development as well.

Similarly, a study by the organization Children in Communication about Migration (CHICAM) found that parents used satellite television to maintain "children's fluency in the home language, while several families also actively encouraged their children to watch national television to assist them in learning the new language." ${ }^{8}$ The CHICAM study also found these transnational children to be wellinformed about global current events. Thus, satellite television, and the complementary ability to participate in national culture from afar, served as a mediating tool used by parents to influence their children's worldview development. Lam and Rosario-Ramos similarly

\footnotetext{
$6 \quad$ Lam and Warriner (2012) 206.

7 Ken Cruickshank, "Literacy in Multilingual Contexts: Change in Teenagers' Reading and Writing," Language and Education 18, 6 (2004): 459-473.

$8 \quad$ Lam and Warriner (2012) 206.
} 
found, in a study of the multilingual digital practices of high schoolaged immigrants, that the majority of the students broadened their worldview through exposure to a variety of national and international news sources. ${ }^{9}$

Finally, several studies focused on how participation in social networking with online communities mediated the development of complex, transnational identities. McGinnis et al., in a multiple case study, argued that "online sites serve as critical spaces for these youth to reflect upon, describe, and struggle with the social and cultural contexts of their offline lives." ${ }^{10}$ In the same vein, Yi, investigating Korean transnational youth, showed how online communities served as a "safe space" for youth to "embrace and explore their transnational and transcultural identities." ${ }^{11}$ Lee, in a look at the use of "Tonglish" on Pacifican Tongan youth websites, discovered that the youth in question were able to debate language use-and thus their own identities-online in a way that would have been impossible within their physical, local communities.

\section{Theoretical Framework}

The theoretical framework for this study is informed by sociocultural mediation and specifically by Appadurai's concepts of flows and scapes. ${ }^{12} \mathrm{I}$ am interested in how students apply practices from one place to situations in another. The sociocultural framework of mediation using tools provides a way of mapping and theorizing

9 Wan Shun Eva Lam and Enid Rosario-Ramos, "Multilingual Literacies in Transnational Digitally Mediated Contexts: An Exploratory Study of Immigrant Teens in the United States," Language and Education 23, 2 (2009): 171-190.

10 Theresa McGinnis, Andrea Goodstein-Stolzenberg and Elisabeth Costa Saliani, "Indnpride": Online Spaces of Transnational Youth as Sites of Creative and Sophisticated Literacy and Identity Work," Linguistics and Education 18, 3 (2008): 299.

11 Youngjoo Yi, "Adolescent Literacy and Identity Construction Among 1.5 Generation Students: From a Transnational Perspective," Journal of Asian Pacific Communication 19, 1 (2009): 117.

12 Arjun Appadurai, Modernity at Large: Cultural Dimensions of Globalization (Minneapolis: University of Minnesota Press, 1996) 32. 
these connections. Also important is the fact that sociocultural theory informs a view of literacy as a socially embedded process. In agreement with the New Literacy Studies (e.g., Brian Street, ${ }^{13} \mathrm{~J}$.

P. Gee ${ }^{14}$ ), I view the act of decoding and making linguistic meaning as inseparable from the social spaces in which those texts are read. As the line between physical and virtual becomes ever more blurry, the social embeddedness of texts becomes more complex and multi-sited. What does it mean to read a digital text within an online community while being physically located within another, perhaps significantly different community? How can this overlap of text and space be productive as well as disjunctive?

Sociocultural theory, and Vygotsky's concept of mediation in particular, provides a way of theorizing about how humans use various tools (including language) to accomplish more psychological and physical work than their natural, biological state allows. ${ }^{15} \mathrm{In}$ contrast to the singular, biological line of development experienced by animals, Vygotsky countered that humans were shaped by a second, socioculturally originating line of psychological development. His findings stood in sharp contrast to the domination of behaviorism within the psychological community of the early 1900s. Rather than simply responding directly to stimuli (as behaviorists would suggest), Vygotsky argued that what separated humans from the apes was their ability to respond indirectly through the use of mediating tools. These tools could be either physical, such as an axe used to chop wood and bring change to the physical environment, or symbolic (semiotic), such as written language used to write a reminder and bring change to the psychological environment. In relation to the current study, I argue that engagement in various forms of digital

13 B. V.Street, ed., Literacy across Educational Ccontexts: Mediating Learning and Teaching (Philadelphia: Caslon, 2005).

14 J. P. Gee, Social Linguistics and Literacies: Ideology in Discourses (London: Routledge, 2007).

15 L. S. Vygotsky, Mind in Society: The Development of Higher Psychological Processes (Cambridge: Harvard University Press, 1978) 46. 
practices discursively mediates language and literacy development in official and non-official spaces of learning.

\section{Flows and Scapes}

Appadurai's flows and scapes provide a helpful metaphor for visualizing the complex movement which defines both globalization and, in Appadurai's view, a new turn in modernity. At the core of his argument is the idea that mass migration and mass media, though not new, have reached such "speed, scale, and volume...." that they have become destabilizing and disjunctive. ${ }^{16}$ In particular, he analyzes this acceleration by naming "five dimensions of global cultural flows that he terms (a) ethnoscapes, (b) mediascapes, (c) technoscapes, (d) financescapes, and (e) ideoscapes. ${ }^{17}$ He refers to them as scapes to emphasize their fluidity, irregularity, and context-dependent inflectedness. Depending on where one stands in the world, how they view the scapes which surround them is potentially quite different.

I take each scape one by one. Ethnoscapes, a term purposefully ambiguous, refers to the "landscape of persons who constitute the shifting world in which we live: tourists, immigrants, refugees, exiles, guest workers, and other moving groups and individuals." ${ }^{18}$ Those who must move, those who can move, and those who fantasize of moving are all included. Technoscapes refer to the "global configuration, also ever fluid, of technology and the fact that technology, both high and low, both mechanical and informational, now moves at high speeds across various kinds of previously impervious boundaries." ${ }^{19}$ Financescapes describe transfers of capital, ranging from cash transactions with a street vendor to the increasingly mysterious and split-second purchases and sales of stocks and other "financial products", facilitated by high-power computer programs. Mediascapes and ideoscapes

\footnotetext{
16 Appadurai, 37.

17 Appadurai, 33.

18 Appadurai, 34.

19 Appadurai, 34.
} 
are interconnected. Mediascapes refer to the various means, both electronic and not, of disseminating information and ideas. These various ideas, images, and possible narratives thus make up ideoscapes.

What might these scapes look like? Take this oversimplified example. A youth moves from one part of the world to another; though in the past she was part of the majority population, she now is a member of a community of refugees who, though sizeable in number, are a minority in their new city. She is now a member of an ethnolinguistic and racial minority. This is a shift in ethnoscape. Perhaps she receives multiple messages about her gender identity (ideoscapes) in her new physical community, but also through local and international media sources (mediascapes), thanks to local and satellite television, as well as the internet (technoscapes). When these possible narratives conflict, they create a disjunctive power in her life.

In regards to language, flowing ethnoscapes, mediascapes, and technoscapes shift locations of language contact and possible spaces of language learning. Jacquemet refers to this "co-presence of multilingual talk (exercised by de/reterritorialized speakers) and electronic media, in contexts heavily structured by social indexicalities and semiotic codes" as transidiomatic practices. ${ }^{20}$ Perhaps, I suggest, these transidiomatic practices are their own scape-linguascapes. As a result of these new shifts, in 2000 Lam urged TESOL to rethink "the relation between identity and literacy development...in the present age of globalization as 'virtual communities' emerge on the Internet and cultural products, symbols, and images circulate transnationally." ${ }^{21}$ The present study aims to investigate how these various scapes flow through and between these 'virtual communities' and physical ones, and in doing so, mediate language learning practices.

20 Marco Jacquemet, "Transidiomatic Practices: Language and Power in the Age of Globalization," Language \& Communication 25, 3 (2005): 265.

21 Wan Shun Eva Lam, "L2 Literacy and the Design of the Self: A Case Study of a Teenager Writing on the Internet." TESOL Quarterly 34, 3 (2000): 457. 


\section{Methodology}

Case studies are defined by their boundedness. In particular, it is "the unit of analysis, not the topic of investigation, (which) characterizes a case study." ${ }^{22}$ Stake adds that "a case is a noun, a thing, an entity; it is seldom a verb, a participle, a functioning." ${ }^{23}$ Miles and Huberman consider a case to be the study of "a phenomenon of some sort occurring in a bounded context." ${ }^{24}$ Thus, in this study, the case-the unit of analysis-is an individual student and the topic is digital literacy practices.

Data collection consisted primarily of two open-ended interviews with the focal participant. Other planned data collection methods, including participant observation both in the participant's home and school, were not approved by my institution's Research Review Board. Thus this study is solely exploratory in nature. Interviews, admittedly inferior methods to observation, were conducted over the phone and recorded using the software AudioNote. Questions focused on: a) language use on- and offline, b) language learning methods, again, both on- and offline, c) general digital media use, d) general studying methods, and e) social networking, both with known and unknown people.

\section{Participant}

The focal participant, Angela, is a twenty year-old female who immigrated from Vietnam with her family when she was thirteen years-old. She grew up speaking Vietnamese; her English study began in the U.S., and in addition she has just begun to study Spanish. Six years ago, when she was a freshman in high school, she was a student in a sheltered Global Studies course that I taught. Today she is

22 Sharan B. Merriam, Qualitative Research: A Guide to Design and Implementation (San Francisco: Jossey-Bass, 2009) 41.

23 Robert E.Stake, Multiple Case Study Analysis (New York: Guilford Press, 2006) 1.

24 Matthew B. Miles and A. Michael Huberman, Qualitative Data Analysis. 2nd ed. (Thousand Oaks, CA: Sage Publications, 1994) 25. 
finishing her second year of coursework at a local community college. She currently lives in her family's home with her mother and brother and works in fast food service in addition to attending school.

\section{Findings and Discussion}

As Lam and Warriner point out, "A transnational optic does not imply that all migrants engage in sustained interactions across borders. Forms of contact and exchange may be selective, ebb and flow, and develop differently through the life cycle." ${ }^{25}$ I found this to be the case in my work as well. In the six years that I have known Angela, her digital and language specific practices have evolved; in particular, leaving high school, getting a job, and attending college shifted both what she did online and with who.

Angela described past use of chat rooms. She said that she spent many hours a week in Yahoo chat rooms, 'hanging out' with strangers and 'speaking' in both Vietnamese and English. However, she indicated that the responsibilities of work and school had shifted not only her use of, but also her opinion of chat rooms.

Well, I was? I like it before, but not anymore. Now I think it is so annoying. I don't know. I think it's so annoying! Cause before, you know, like mostly I'm I don't go to um work. I just go home and go school and I just stay home by myself and so I get really boring. And I just jump on the computer and, I mean Yahoo and just talk to a bunch of weird people and I was like you make me laugh, you're funny! I'll be your friend. Like that. But right now I work and I go to school. I mean, I feel like I don't even know those people. I'd rather want make friends with people that I met in the real world, like, you know, face to face conversations, not somebody like online, just like chat, so far away. I mean, those sort of yeah I talk to you today, but tomorrow, I was like "do you remember me?" "No, not really." 
When asked what social media she uses today, Angela replied, without hesitation, that it was Facebook. Why?

Well, it's just that (laugh) I feel like it connect me to connected me with my old friends. You know how we're uh graduated it's really really rare that you see your old friends back. Talking to them on facebook. Like Kim. Now she's like in NWU, and so it's really far away. I don't think she come home every day so I mean by that time we can check each other.

The key point here is that she now uses social media, specifically Facebook, because it allows her to connect with people she knows in real life. Chat rooms lost their appeal because they lacked this connection to reality. Contrary to what I had expected, in the case of at least this one youth-Angela-it is the real, not virtual relationships that were the key driver for online communication. Conversations did flow through the technoscapes of social media, via internet and text messaging, but primarily intersected within physical, not virtual, ethnoscapes (communities of people).

In regards to language use, it appears that because Angela went online primarily for pre-existing relationships, language learning, when it did happen, was purely consequential. That said, relationships, especially a romantic one with a Spanish speaker, provided a strong motivation to both learn Spanish, and to experiment with her Spanish interlanguage when online. Thus, the relationship, though primary in encouraging online, social media usage, provided a strong enough motivation to learn, practice, and be creative with new language(s).

This finding was consistent with comments she made about her mother's insistence that she and her siblings maintain their Vietnamese. Angela saw being multilingual as an asset, primarily for the access it gave her to communities:

I kinda glad (that my mother made me speak Vietnamese at home) cause I mean I feel like it's good to know like a multiple language. 
Yeah, I don't know. I feel like it's really cool if I speak like so many languages and I understand like what they saying and I feel like I'm like part of it too. Yeah, and like, yeah, I speak their language, yeah talk to me like you know it's awesome! Yeah, and I mean, it's like even if I want to go travel in like French or in Mexico, I understand little bit you know. Not just like I travelled there and I don't understand anything. I feel like, uh, I'm lost. I don't belong there.

Using Appadurai's concept of scapes, I would argue that Angela saw her unique linguascape as a tool she could use to navigate in new places with different ethnoscapes. Here again, it was the prospect of speaking with real communities of speakers - both current and imagined future speakers - which motivated language study.

Angela also defined her linguistic knowledge, her linguascape, broadly. When asked if she ever learned new English or Vietnamese vocabulary playing online games, she interpreted the question to mean both newly created words and simply words that were new to her.

Ang: Uh, yes. Even words that they just make it up. They don't say you know, like the correct way, they say like short. It's the same thing in Vietnamese, they don't say it a lot like that, the correct way, they make up new words and so they make faster, faster to type it. But sometime if you don't understand you will you will think it and you will understand it in a different way, and that could be wrong. But absolutely I learn a lot of new words in um Vietnamese, if I play games with my Vietnamese friends.

Beth: It's probably really similar with texting, right? Like a lot of words get shortened, I know, in English, but Vietnamese too, right?

Ang: Yes, Absolutely.

Beth: Do your friends, like your Vietnamese friends ever mix, and you, when you're texting back and forth you mix English and Vietnamese?

Ang: Always! (laughing) Cause um, I don't know if, I guess some words that I don't even know how to say in Vietnamese, so I 
just like yeah, it just pop up in my head like oh yeah this word mean that in English, so I just text that. The other person will know what I mean.

Though not useful in academic settings, these abbreviated words and phrases, typically associated with youth culture, are essential for communicating within the target culture and language of 'youth talk.' Further, they are a type of specialist (insider) language; though the content of the talk is not directly transferable into school environments, the practice of speaking with co-specialists is.

Angela's digital use was not limited to social media; she was a consumer of video content as well. She frequently streamed Korean dramas, watching them with Vietnamese subtitles. Interestingly, though she didn't see using Vietnamese subtitles as instrumental in maintaining her Vietnamese, she felt that using English subtitles $a b$ solutely helped her learn new words in English.

Beth: Do you ever feel like when you watch movies or dramas of like okay, sort of two questions. So if you watch a movie that has the Vietnamese subtitles, do you feel like that's sort of keeping your Vietnamese fresh?

Ang: Um, I don't think so, I mean, I don't think it's really (.) gonna keep me like remember.

Remember as much as I talk it like.

Beth: What about, do you think it's the same for you with English, like if you watch a movie with English subtitles do you feel like it helps you learn new words, or like the most-

Ang: Yeah. It's like absolutely.

Thanks to the technoscape of the internet and her linguascapes of Vietnamese and English, Angela was able to interact with mediascapes coming out of Korea. Though her intent for watching the videos was to view the mediascape(s), she indirectly exercised and extended her existing linguascapes using the mediating tool of 
subtitles. I would argue that, though she did not consciously realize it, the use of subtitles in both Vietnamese and English were useful language maintenance / learning practices.

\section{Conclusion}

In this paper I have begun exploring the digital literacy practices of one Vietnamese-American young woman. Though limitations in data collection narrowed the potential scope of this project, the case study is not without findings and potential implications. Centrally important for Angela's online use were offline relationships which served as authentic draws to engage in social media. This finding complicates assumptions about 'the digital generation'-that they are online 24/7/365 and primarily engaged with people they have never met face-to-face.

When online, interactions on social media and other websites often did lead to incidental opportunities for language learning. Thus, digital media was used as a mediating tool to maintain initally offline relationships; the relationships themselves, via the tool of the internet, then mediated language learning and maintenance practices. This study suggests that social media can be a 'location' for furthering new friendships and practicing the youth vernacular of the target language. Most importantly, though, this look into digital practices serves as a welcome reminder that, at the end of the day, digital tools are just that-tools. It is relationships, both those inside and outside the classroom, which foster community and learning. 